\title{
El control de convencionalidad y la prohibición de la discriminación en Chile*
}

Recibido: 13 de agosto de 2018 • Aprobado: 20 de noviembre de 2018

https://doi.org/10.22395/ojum.v18n36a3

Gonzalo Aguilar Cavallo*

\begin{abstract}
RESUMEN
En este trabajo se examinan casos de discriminación para determinar si la Corte Suprema chilena realiza un control de convencionalidad en la materia. La hipótesis que se propone es que la prohibición de la discriminación ha sido un terreno fértil, aunque excepcional, en el que la Corte Suprema ha realizado un control de convencionalidad. Se examina cómo y en qué medida el máximo tribunal del poder judicial lleva a cabo este tipo de control. La Corte Suprema utiliza las convenciones internacionales, el soft law y las opiniones de los órganos de tratados para mejorar la protección contra la discriminación.

Palabras clave: igualdad; prohibición de la discriminación; control de convencionalidad; discriminación interseccional; discriminación estructural.
\end{abstract}

* El presente artículo es producto de un trabajo de investigación que se realiza en el seno del Centro de Estudios Constitucionales de Chile dentro de la línea de investigación de control de convencionalidad.

** Abogado, Chile, doctor en Derecho, Madrid, España, magíster en Relaciones Internacionales, Madrid, España, máster en Derechos Humanos y Derecho Humanitario, Universidad de Paris II Pantheon-Assas, Francia, posdoctorado en el Max Planck Institute for Comparative Public Law and International Law, Heidelberg, Alemania, profesor de Derecho Constitucional, Internacional, Ambiental y Derechos Humanos. Director de la Maestría en Derecho Constitucional del Centro de Estudios Constitucionales de Chile y subdirector del Centro de Estudios Constitucionales de Chile, Universidad de Talca, Santiago, Chile. Correo electrónico: gaguilarch@hotmail.com 


\section{The Control of Conventionality and the Prohibition of Discrimination in Chile}

\section{ABSTRACT}

This paper addresses discrimination case law in order to determine whether the Chilean Supreme Court carries out a conventionality control on that matter. It is suggested that the prohibition of discrimination has been a fertile - though still exceptional — ground for performing a conventionality control. We also analyze how and to what extent the Supreme Court carries out this type of control. The Supreme Court refers to international conventions, soft law norms and the United Nations treaty bodies' case law in order to enhance the protection against discrimination.

Keywords: equality; prohibition of discrimination; control of conventionality; intersectional discrimination; structural discrimination.

\section{0 controle de convencionalidade e a proibição da discriminação no Chile}

\section{RESUMO}

Neste trabalho são examinados casos de discriminação para determinar se a Corte Suprema chilena realiza um controle de convencionalidade na matéria. A hipótese proposta é de que a proibição da discriminação tem sido um terreno fértil, embora excepcional, no qual a Corte Suprema vem realizando um controle de convencionalidade. Examina-se como e em que medida o máximo tribunal do poder judicial executa esse tipo de controle. A Corte Suprema utiliza as convenções internacionais, o soft law e as opiniões dos órgãos de tratado para melhorar a proteção contra a discriminação.

Palauras-chave: igualdade; proibição da discriminação; controle de convencionalidade; discriminação interseccional; discriminação estrutural. 


\section{INTRODUCCIÓN}

Aun cuando, a veces, nos parezca increíble y pensemos que ciertos acontecimientos solo se pueden encontrar en una novela surrealista, la realidad cotidiana nos sorprende. En este trabajo nos referiremos a actos de discriminación que afectan a miembros de pueblos indígenas, en particular, mapuches, a mujeres privadas de libertad, a niños, niñas y adolescentes, a personas con discapacidad y a trabajadores. Estos actos que representan la negación de la dignidad inmanente del ser humano cuestionan los procesos civilizatorios y resquebrajan el principio elemental de humanidad, que se cuenta entre aquellos que el derecho internacional refiere como principios reconocidos por las naciones civilizadas (Estatuto de la Corte Internacional de Jus ticia, artículo 38.1. c). En este contexto, el derecho a la igualdad y la prohibición de la discriminación emergen como un derecho fundamental en el más amplio sentido de la palabra. En sociedades desiguales, como la chilena, este derecho adquiere aún mayor relevancia.

¿Cuáles serían los principales criterios orientadores, tanto para poderes públicos como privados, en orden a suprimir comportamientos u omisiones que tengan como causa, o bien, como resultado una diferencia de trato basada en alguna de las categorías prohibidas antes mencionadas, a saber, el origen étnico, el género, la edad, discapacidad, la clase y condición social, etc.? En nuestra opinión, dichos principios o directrices se encuentran o deberían encontrarse en la base de un sistema jurídico democrático fundado en un enfoque de derechos humanos. En el siglo XXI, este enfoque se ha convertido en una rica fuente legitimadora del ejercicio del poder estatal y asimismo del poder de los particulares.

En este trabajo no vamos a examinar en qué consiste el control de convencionalidad, ni su debate y polémica teórica. Tampoco vamos a examinar los tipos de control de convencionalidad, ni sus características ni su comparación con el control de constitucionalidad. Este trabajo pretende simplemente, mediante un examen breve de sentencias recientes emanadas de la Corte Suprema chilena en materia de igualdad, determinar si este tribunal efectúa un control de convencionalidad y cómo lo lleva a cabo. Este tipo de sentencias no constituyen la regla general y han sido seleccionadas por su actualidad y excepcionalidad. En consecuencia, este trabajo es eminentemente de análisis jurisprudencial y sigue un método de casos.

El trabajo se divide en dos partes. La primera, aborda una referencia al control de convencionalidad y, junto con ello, el análisis de interesantes casos que ha examinado la Corte Suprema respecto de alguna de las categorías prohibidas antes mencionadas. 
En la segunda, a partir de este análisis de casos, se analizan brevemente algunos de los principios básicos que el Estado debe respetar en orden a evitar incurrir en conductas u omisiones basadas en discriminación por alguna de las categorías aludidas.

\section{EL CONTROL DE CONVENCIONALIDAD}

Quizá existen pocos temas que hayan hecho correr tanta tinta recientemente entre la doctrina latinoamericana como es el control de convencionalidad (Olano 2016; Castilla Juárez, 2016; Risso, 2016). Desde el primer momento de su formulación oficial, esta generó adeptos y detractores (Ferrer, 2011; Nogueira, 2012)' . En esta parte no haremos un examen de este interesante debate doctrinario, sino más bien, tomaremos la doctrina, tal como es planteada por la jurisdicción interamericana, como puerta de entrada al análisis más detenido de los estándares mínimos desarrollados por la Corte Interamericana de Derechos Humanos (Corte IDH) en materia de igualdad y prohibición de la discriminación.

\subsection{Hacia un constitucionalismo de los derechos}

El control de convencionalidad es una doctrina explicitada por la Corte IDH que indica que los Estados parte en la Convención Americana sobre Derechos Humanos (CADH) y, por lo tanto, todos sus órganos, están obligados a velar por el cumplimiento de las normas del tratado tomando en consideración la interpretación que de dichas normas ha realizado la propia Corte Interamericana como intérprete auténtico y final de la Convención (Nogueira, 2015; Núñez, 2015; Torres, 2015-2016). Esta doctrina es una especificación de un principio clásico del derecho internacional. Este principio consiste en que un Estado que ha consentido en obligarse por un tratado debe cumplir íntegramente, tanto en el ámbito internacional como interno con dicha obligación internacional, adoptando todas las medidas necesarias para hacer efectivos los derechos derivados de dicha obligación, así se señala en el artículo 2 de la Convención Americana sobre Derechos Humanos (OEA, 1969; Castilla, 2014).

En nuestra visión, el control de convencionalidad se ha convertido en una herramienta jurídica eficaz para satisfacer la noción de estándar mínimo de derechos humanos (Ruiz-Morales, 2017; Molina, 2018). Del mismo modo, el control de convencionalidad se ha convertido en una vía apropiada a través de la cual se puede desarrollar un fructífero diálogo entre jueces, especialmente, de derechos humanos (Miranda Bonilla, 2015; Aguilar, 2017).

Para una visión crítica: Silva, 2016, pp. 101-142; Fuenzalida, 2015, pp. 171-192. Para una discusión del control de convencionalidad que ha trascendido a Europa: Ruiz-Morales, 2017, pp. 129-160; Nuevo, 2015, pp. 141-160; Iglesias, 2017, pp. 191-222; Martínez, 2016, pp. 94-119. 
El control de convencionalidad se configura como una manifestación expresa del constitucionalismo global, entendiendo este último término como aquel en el que es posible encontrar ciertas bases comunes o ciertos pilares comunes entre diversos órdenes constitucionales estatales que tienden a reproducir lo que podríamos denominar un patrón constitucional (Díaz, 2016). Estos elementos constitucionales mínimos comunes se pueden identificar en el Estado de Derecho, la democracia y los derechos humanos (Julios-Campuzano, 2009; Ferrajoli, 1998). El aporte del control de convencionalidad al proceso de construcción del constitucionalismo global reside, precisamente, en este último componente. Uno de los mecanismos más utilizados en las últimas décadas para este proceso de construcción de mínimos comunes y compartidos, a nivel regional e incluso planetario, en el ámbito de los derechos humanos ha sido el desarrollo del diálogo entre jueces (Ansuátegui, 2015; Rodríguez, 2017a). Entre otras cosas, este diálogo es el resultado, deliberada o accidentalmente, desde un punto de vista sustancial, de la emergencia de los derechos humanos como derechos universales, y desde un punto de vista procesal, de la puesta en marcha de los mecanismos internacionales, universales y regionales, de protección de los derechos humanos (Català, 2015; Camarillo, 2016). En este contexto, se podría plantear el control de convencionalidad como una explicitación de esta contribución regional americana al impulso de un constitucionalismo global (Urueña, 2013; Acosta 2013)². Además de todo lo anterior, nos referimos a constitucionalismo global porque consideramos los derechos humanos como enunciados jurídicos con carácter constitucional cualquiera sea el instrumento en el que se encuentren y cualquiera sea el ámbito geográfico en el que se apliquen: nacional, internacional e, incluso, supranacional (Guastini, 1999).

Si un juez nacional asume que, entre sus obligaciones, como agente del Estado, se encuentran el respeto, la protección y la garantía de los derechos humanos, ya sea que estos emanen del derecho interno o bien, del derecho internacional de los derechos humanos, se transforma efectivamente en el juez común de derechos humanos (Montesinos, 2016-2017; Carrillo y Espósito, 2011). Miranda (2015) señala que "los jueces nacionales se convierten en los primeros jueces interamericanos. Son los que tienen la mayor responsabilidad para armonizar la legislación nacional con los parámetros interamericanos" (p. 23). En caso de antinomias entre la norma interna y la internacional de derechos humanos, el juez nacional, siguiendo el fin para el cual fueron concebidos los derechos humanos, debería optar por aquella norma o interpretación más favorable para el individuo o menos restrictiva para sus derechos, de acuerdo con el principio pro homine (Díaz, Paz y González, 2017; Risso, 2016). En este sentido:

El control de convencionalidad implica la necesidad dedespojarse de una serie importante de lastres histórico-dogmáticosmuy arraigados en la ciencia jurídica,

Para una visión crítica ver Escobar-García, 2012, pp. 79-118. 
derribar una serie de mitos (v.gr. la supremacía exclusiva de la Constitución) y, en definitiva, un nuevo paradigma del Derecho Público de los países del sistema interamericano (Jinesta, 2012).

En este sentido, el control de convencionalidad es un recordatorio para todos los órganos del Estado, especialmente, para el juez nacional, de su obligación de velar, en el orden jurídico interno del Estado, por el cumplimiento de los tratados internacionales de acuerdo con la interpretación que de ellos han realizado los órganos autorizados por el propio Estado para realizarla. En este contexto, el control de convencionalidad que más tinta ha dejado correr es el referido a la Convención Americana sobre Derechos Humanos y, consecuentemente, a la interpretación autorizada que la Corte Interamericana de Derechos Humanos efectúa de las normas de la mencionada Convención, como intérprete final de la misma.

¿Cómo debe realizarse el control convencional de conformidad con los instrumentos internacionales de protección de derechos humanos? Los tratados internacionales de derechos humanos ratificados por un Estado generan obligaciones jurídicas para los mismos. Estas obligaciones jurídicas son para el Estado, lo que implica cada uno de los órganos del mismo. Ello incluye a los jueces. Los jueces tienen asignada la tarea jurisdiccional dentro del sistema de distribución de funciones estatales. Dentro de esta tarea jurisdiccional, esto es, la recta administración de justicia, se incluye la garantía en el disfrute pleno de los derechos. Los jueces, al garantizar el goce efectivo de los derechos de los individuos, comunidades y pueblos, está obligado a velar por el cumplimiento de los tratados internacionales de derechos humanos, considerando la interpretación que ha realizado el órgano autorizado por los mismos Estados para ello. Si el estándar proveniente de esta operación protege de mejor manera que el estándar interno los derechos de las personas, el juez debería preferir, en ese caso, el estándar internacional.

Tratándose de los estándares mínimos, la Corte Interamericana de Derechos Humanos, a través de sus sentencias, ha definido un núcleo sustancial de criterios jurídicos que permitirían a los jueces nacionales inspirarse, respaldarse y orientarse cuando tengan que pronunciarse respecto del derecho a la igualdad y la prohibición de la discriminación.

\subsection{La convencionalidad y el combate a la discriminación}

Los jueces nacionales se encuentran obligados a aplicar las normas internacionales que contienen el derecho a la igualdad y la prohibición de la discriminación por diversas razones. En primer lugar, el artículo 5 inciso $2^{\circ}$ de la Constitución chilena así se lo exige al señalar que: 
El ejercicio de la soberanía reconoce como limitación el respeto a los derechos esenciales que emanan de la naturaleza humana. Es deber de los órganos del Estado respetar y promover tales derechos, garantizados por esta Constitución, así como por los tratados internacionales ratificados por Chile y que se encuentren vigentes.

Y, en segundo lugar, el derecho internacional así se lo impone al Estado. En efecto, si se considera solo el derecho interamericano, cabe señalar el artículo 1 y 2 de la CADH y se refuerza esta posición, si se le concuerda con el artículo 26 y 27 de la Convención de Viena sobre Derecho de los Tratados (CVDT) de 1969. Sabemos que tanto el argumento constitucional como internacional antes mencionado es objeto de debate y contraste ${ }^{3}$.

La Corte Interamericana de Derechos Humanos ha sostenido, con base en el principio de complementariedad que inspira el sistema, que cuando ya se ha establecido un estándar en el orden internacional, no es necesario que los casos se lleven al sistema interamericano, sino que los jueces nacionales están en condiciones de resolverlos considerando los estándares internacionales de derechos humanos. Por ello, interesa, como veremos a continuación, determinar principios elementales y estándares claves provenientes desde el sistema interamericano respecto del derecho a la igualdad y la prohibición de la discriminación.

\subsubsection{Principios elementales para prevenir, sancionar y reparar la discriminación}

Discriminación es un acto u omisión, por esencia, violatorio de derechos humanos. Así como ocurre con la Constitución Política de la República, ni la Convención Americana sobre Derechos Humanos ni el Pacto Internacional de Derechos Civiles y Políticos contienen una definición explícita del concepto de discriminación. En el caso Duque, la Corte Interamericana de Derechos Humanos reiteró, una vez más, el concepto que resulta del corpus iuris internacional. Así, discriminación es:

Toda distinción, exclusión, restricción o preferencia que se basen en determinados motivos, como la raza, el color, el sexo, el idioma, la religión, la opinión política o de otra índole, el origen nacional o social, la propiedad, el nacimiento o cualquier otra condición social, y que tengan por objeto o por resultado anular o menoscabar el reconocimiento, goce o ejercicio, en condiciones de igualdad, de los derechos humanos y libertades fundamentales de todas las personas (Corte IDH, 2016, párr. 6).

Cabe también agregar que la enumeración de las categorías prohibidas de discriminación contenidas en el derecho internacional de los derechos humanos, como

3 Aquí solo mencionaremos alguna doctrina crítica, pero no desarrollaremos los argumentos porque, como se ha señalado, el examen de estos argumentos no es el objetivo central de este trabajo (Cfr. Fuentes, 2007, pp. 2-35; Contesse, 2013; Henríquez, 2014, pp. 113-141). 
estándar mínimo, no es taxativa ni mucho menos exhaustiva y se efectúa a mero título ejemplar. En efecto, la Corte IDH (2017) en opinión consultiva sobre Identidad de género e igualdad y no discriminación a parejas del mismo sexo, ha indicado que:

Los criterios específicos en virtud de los cuales está prohibido discriminar, según el artículo 1.1 de la Convención Americana, no constituyen un listado taxativo o limitativo sino meramente enunciativo. Es así como, la redacción de dicho artículo deja abiertos los criterios con la inclusión del término "otra condición social" para incorporar así a otras categorías que no hubiesen sido explícitamente indicadas. La expresión "cualquier otra condición social" del artículo 1.1. de la Convención debe ser interpretada por la Corte, en consecuencia, en la perspectiva de la opción más favorable a la persona y de la evolución de los derechos fundamentales en el derecho internacional contemporáneo (párr. 70).

Como se puede apreciar, la visión de la Corte IDH (2017, párr. 69) compartida por la Corte Europea de Derechos Humanos, reside en la interpretación evolutiva que considera a los tratados de derechos humanos como instrumentos vivos, "cuya interpretación tiene que acompañar la evolución de los tiempos y las condiciones de vida actuales".

La discriminación implica la negación misma del principio de igualdad intrínseca a toda la familia humana. En el caso Atala, la Corte Interamericana de Derechos Humanos (Corte IDH, 2012) sostuvo que:

La noción de igualdad se desprende directamente de la unidad de naturaleza del género humano y es inseparable de la dignidad esencial de la persona, frente a la cual es incompatible toda situación que, por considerar superior a un determinado grupo, conduzca a tratarlo con privilegio; o que, a la inversa, por considerarlo inferior, lo trate con hostilidad o de cualquier forma lo discrimine del goce de derechos que sí se reconocen a quienes no se consideran incursos en tal situación (párr. 79).

Si bien el principio de prohibición de la discriminación, como en general ocurre con las normas de derechos humanos, está en principio dirigido a los órganos del Estado, también alcanza acciones u omisiones de particulares. A este respecto, la Corte IDH, en el caso Duque, ha reiterado el criterio de las obligaciones positivas de los Estados en materia de derechos humanos. En efecto, los jueces interamericanos (Corte IDH, 2016, párr. 92) han señalado que:

Los Estados están obligados a adoptar medidas positivas para revertir o cambiar situaciones discriminatorias existentes en sus sociedades, en perjuicio de determinado grupo de personas. Esto implica el deber especial de protección que el Estado debe

${ }_{4}$ Cfr. Corte IDH, 1999, El derecho a la información sobre la asistencia consular en el marco de las garantías del debido proceso legal. Opinión consultiva párr. 114; 2005, caso de la Masacre de Mapiripán vs. Colombia, párr. 106; 2012, caso Atala Riffo y niñas vs. Chile, párr. 83. 
ejercer con respecto a actuaciones y prácticas de terceros que, bajo su tolerancia o aquiescencia, creen, mantengan o favorezcan las situaciones discriminatorias ${ }^{5}$.

Desde el punto de vista de la jerarquía material del derecho a la igualdad y de la prohibición de la discriminación cabe recordar que la jurisprudencia de la Corte IDH ha sostenido reiteradamente que este derecho y la prohibición que le acompaña han alcanzado el estatus de una norma de ius cogens. En efecto, los jueces interamericanos han señalado lo siguiente:

La jurisprudencia de la Corte (Condición Jurídica y Derechos de los Migrantes Indocumentados. Opinión Consultiva, párr. 101; 2012, Caso Atala Riffo y niñas vs. Chile, párr. 79.) también ha indicado que, en la actual etapa de la evolución del derecho internacional, el principio fundamental de igualdad y no discriminación ha ingresado en el dominio del jus cogens. Sobre él descansa el andamiaje jurídico del orden público nacional e internacional y permean todo el ordenamiento jurídico.

Por último, como principio elemental, la Corte IDH (2016) ha, asimismo, reiterado que cuando se está en presencia de una diferencia de trato por alguna categoría prohibida, se transforma en sospechosa, y ello tiene la virtud de operar una alteración en el onus probandi, de tal manera que es el demandado, en general, el Estado, quien debe demostrar que no incurrió en la acción discriminatoria o que la diferencia de trato tiene una justificación objetiva, razonable y proporcionada. En el caso Duque, los jueces interamericanos reiteraron que:

Una diferencia de trato es discriminatoria cuando la misma no tiene una justificación objetiva y razonable, es decir, cuando no persigue un fin legítimo y no existe una relación razonable de proporcionalidad entre los medios utilizados y el fin perseguido. Asimismo, este Tribunal (Corte IDH, 2016, párr. 106) estableció que tratándose de la prohibición de discriminación por una de las categorías protegidas contempladas en el artículo 1.1 de la Convención, la eventual restricción de un derecho exige una fundamentación rigurosa, lo cual implica que las razones utilizadas por el Estado para realizar la diferenciación de trato deben ser particularmente serias y estar sustentadas en una argumentación exhaustiva ${ }^{6}$. En el presente caso, el Estado no brindó una explicación sobre la necesidad social imperiosa o la finalidad de la diferencia de trato, ni sobre por qué el hecho de recurrir a esa diferenciación es el único método para alcanzar esa finalidad (Corte IDH, 2016, párr. 107).

5 Cfr. Corte IDH, 2003, Condición jurídica y derechos de los migrantes indocumentados, opinión consultiva, párr. 104; 2010, caso comunidad indígena Xákmok Kásek vs. Paraguay, párr. 271; 2014a, caso Norín Catrimán y otros vs. Chile, párr. 201; 2014b, caso Espinoza Gonzáles vs. Perú, párr. 22; Comité de Derechos Humanos, 1989, párr. 6 y 10).

6 Cfr. Corte IDH, 2002, párr. 46; 2014b, párr. 219; 2014a, párr. 200; 2015a, párr. 257. Asimismo, mutatis mutandi, corte IDH, 2012, párr. 124; "La Corte resalta que tratándose de la prohibición de discriminación por una de las categorías protegidas contempladas en el artículo 1.1 de la Convención, la eventual restricción de un derecho exige una fundamentación rigurosa y de mucho peso, invirtiéndose, además, la carga de la prueba, lo que significa que corresponde a la autoridad demostrar que su decisión no tenía un propósito ni un efecto discriminatorio"; Corte IDH, 2015b, párr. 228. 


\subsubsection{Algunos estándares internacionales y clasificaciones relativas a la prohibición de la discriminación}

En esta parte, pretendemos abordar brevemente los principios aplicables a la discriminación interseccional, luego, abordaremos los principios aplicables a la discriminación estructural en relación, específicamente, con las categorías prohibidas que se han mencionado precedentemente. Nos gustaría reiterar desde ya que cuando hablamos de discriminación nos estamos refiriendo a actos u omisiones que implican un trato diferenciado el cual es irracional o arbitrario, subjetivo o desproporcionado. Ahora bien, evidentemente no todo trato diferenciado es discriminatorio. Dicho de otro modo, un trato diferenciado no es discriminatorio si es racional, objetivo y proporcionado (Corte IDH, 2015a, párr. 274).

\subsubsection{Discriminación interseccional}

La discriminación interseccional es una discriminación en la cual concurren dos o más categorías prohibidas las cuales producen un impacto en el goce pleno de los derechos del afectado que es superior a la simple sumatoria de cada una de las vulneraciones discriminatorias por separado, generándose consecuencias ampliadas en la afectación de los derechos de la víctima.

La Corte Interamericana de Derechos Humanos abordó esta situación en el impactante caso González Lluy (2015a). En este caso, el juez y actual Presidente de la Corte IDH, Ferrer MacGregor, explica con precisión esta figura. En efecto, señala que:

No toda discriminación múltiple sería discriminación interseccional. La interseccionalidad evoca un encuentro o concurrencia simultánea de diversas causas de discriminación. Ello activa o visibiliza una discriminación que sólo se produce cuando se combinan dichos motivos. La interseccionalidad constituye un daño distinto y único, diferente a las discriminaciones valoradas por separado. Ninguna de las discriminaciones valoradas en forma aislada explicaría la particularidad y especificidad del daño sufrido en la experiencia interseccional (párr. 10 y 12).

\subsubsection{Discriminación estructural}

La discriminación estructural es una discriminación cultural, enraizada en la vida y en la forma de ser de una determinada sociedad. Esta discriminación no es un acto aislado de tal o cual autoridad o privado, sino más bien que se trata de una discriminación omnipresente que forma parte de una herencia cultural de una determinada sociedad localizada en un espacio geográfico e histórico particular. En este sentido, Pelletier ha afirmado que:

La discriminación estructural o "desigualdad estructural" incorpora datos históricos y sociales que explican desigualdades de derecho (de jure) o de hecho (de 
facto), como resultado de una situación de exclusión social o de 'sometimiento' de [grupos vulnerables] por otros, en forma sistemática y debido a complejas prácticas sociales, prejuicios y sistemas de creencias. La discriminación estructural puede presentarse en una zona geográfica determinada, en todo el Estado o en la región (Pelletier, 2014).

La Corte IDH (2010, caso comunidad indígena Xákmok Kásek vs. Paraguay) ha indicado a este respecto, que:

Los Estados están obligados a adoptar medidas positivas para revertir o cambiar situaciones discriminatorias existentes en sus sociedades, en perjuicio de determinado grupo de personas. Esto implica el deber especial de protección que el Estado debe ejercer con respecto a actuaciones y prácticas de terceros que, bajo su tolerancia o aquiescencia, creen, mantengan o favorezcan las situaciones discriminatorias (párr. 271).

\section{LA CORTE SUPREMA ANTE EL CONTROL DE CONVENCIONALIDAD Y LA PROHIBICIÓN DE LA DISCRIMINACIÓN}

$\mathrm{Si}$, efectivamente, los jueces nacionales -convirtiéndose en los jueces comunes de derechos humanos-aplican las normas convencionales sobre el derecho a la igualdad y la prohibición de la discriminación, y, en este procedimiento, eventualmente, recurren a la interpretación contenida en la jurisprudencia elaborada por el órgano autorizado para ello, entonces, los jueces nacionales realizan control de convencionalidad.

Entonces, la pregunta que nos planteamos es la siguiente. ¿̇a Corte Suprema de Chile efectúa un control de convencionalidad en las sentencias sobre discriminación? ¿O bien, realiza el comportamiento que la Corte IDH describe al momento de definir el control de convencionalidad? ¿Este control de convencionalidad es explícito o implícito? ¿El control es respecto de la norma de la Convención o respecto de la interpretación proporcionada por la Corte IDH en sus sentencias? A continuación, analizaremos algunas sentencias de la Corte Suprema de Chile que se han pronunciado sobre el derecho a la igualdad y la prohibición de la discriminación, a fin de intentar abordar las respuestas a estas interrogantes.

\subsection{Mujeres indigenas privadas de libertad y discriminación interseccional}

En el año 2016, la Corte Suprema (Rol n. ${ }^{\circ}$ 92.795-2016) conoció de un caso que nos ha dejado pasmados (Lorenza Cayuhan). Una mujer mapuche, privada de libertad, dio a luz a su hija engrillada a la cama del hospital. En este caso, según la sentencia, la diferencia de trato proporcionada por la Gendarmería se basaba, entre otras cosas, porque se trataba de una mujer mapuche. 
La Corte Suprema, en una sentencia remarcable, acoge la acción de amparo y, asumiendo la jurisprudencia de la Corte Interamericana de Derechos Humanos, señala expresamente que se trata de una situación de discriminación interseccional, una de cuyas categorías prohibidas es el origen étnico de Lorenza Cayuhan Llebul. Esto es, la Gendarmería se comportó de este modo, manteniéndola engrillada, entre otras cosas, porque era mapuche. En efecto, los jueces supremos (consid. $15^{\circ}$ ) afirmaron que "es posible constatar indicios que permiten tener por acreditado que el maltrato recibido por la amparada también encuentra explicación en su pertenencia a una comunidad mapuche, lo que refuerza el origen discriminatorio de las actuaciones de Gendarmería." Pero, además, la Corte Suprema resalta que:

No puede dejar de observarse que la vulneración de derechos en que Gendarmería de Chile ha incurrido en contra de la amparada, como ha sido demostrado, constituye también un acto de discriminación en su condición de mujer, pues el trato recibido por ésta de parte de los agentes estatales desconoció dicho estado de vulnerabilidad y, por ende, de necesidad de protección, en circunstancias que, desde una perspectiva de igualdad de género, se debió haber tomado en consideración la situación particular que experimentaba al acercarse el proceso del parto -más aún en las difíciles circunstancias de salud y de privación de libertad en que éste se desarrolló-, como, por otro lado, la especial significación vital para ella del mismo, sobre todo dentro de la comunidad mapuche a la que pertenece, y el impacto negativo que una aplicación no diferenciada de las normas y reglamentos penitenciarios podía ocasionar en aquella mujer.

Esa aplicación no diferenciada de las normas y reglamentos penitenciarios alude a una suerte de acción afirmativa por parte de los agentes del Estado, en este caso de la Gendarmería de Chile que se requiere, respecto de Lorenza Cayuhan, no solo por el hecho de ser mujer privada de libertad en estado de gravidez, sino particularmente, porque pertenece a la comunidad mapuche, con una identidad cultural especialmente protegida por el derecho internacional de los derechos humanos, que debe ser respetada por todos.

En este caso, la Corte Suprema (2016) efectúa un control de convencionalidad, desde el momento en que declara que el actuar de la Gendarmería contraviene tanto la normativa interna como la internacional. En cuanto a esto último, se refiere a la Convención Americana sobre Derechos Humanos, al Pacto Internacional de Derechos Civiles y Políticos, a la Convención Interamericana para Prevenir, Sancionar y Erradicar la Violencia contra la Mujer -conocida como Convención de Belem Do Pará- (consideración $13^{\circ}$ ) y a la Convención sobre la Eliminación de todas las formas de Discriminación sobre la Mujer -conocida como Cedaw-, (consideración $14^{\circ}$ ) estimando que estas normas "tienen primacía incluso por sobre las normas del derecho interno, según lo preceptuado en el artículo $5^{\circ}$ de la Carta Fundamental" (consideración $8^{\circ}$ ). 
Sin embargo, al realizar este control, los jueces del máximo tribunal chileno, no solo aluden a las normas de hard law, sino también recurren a las normas de soft law del derecho internacional de los derechos humanos, tales como las Reglas Mínimas de las Naciones Unidas para el tratamiento de los reclusos (Reglas de Mandela) y las Reglas de las Naciones Unidas para el tratamiento de las reclusas y medidas no privativas de la libertad para las mujeres delincuentes, (Reglas de Bangkok), o bien, los Principios y Buenas Prácticas sobre la Protección de las Personas Privadas de Libertad en las Américas y el Conjunto de Principios para la protección de todas las personas sometidas a cualquier forma de detención o prisión (consideración $14^{\circ}$ ). En este proceder, la Corte Suprema se asume verdaderamente como un tribunal de derechos humanos ya que se produce una notable sincronía con el razonamiento realizado por las Cortes Internacionales Regionales de Derechos Humanos.

Asimismo, reveladoramente, la Corte Suprema (2016) utiliza en su razonamiento en materia de derecho a la igualdad y prohibición de la discriminación la interpretación autorizada de los órganos de tratados pertinentes. En efecto, para establecer el principio de igualdad entre un hombre y una mujer, se recurre a la Recomendación General n. 25 del Comité de la Cedaw, que señala que:

Un enfoque jurídico o pragmático puramente formal, no es suficiente para lograr la igualdad de facto con el hombre, que el comité interpreta como igualdad sustantiva. Además, la Convención requiere que la mujer tenga las mismas oportunidades desde un primer momento y que disponga de un entorno que le permita conseguir la igualdad de resultados. No es suficiente garantizar a la mujer un trato idéntico al del hombre. También debe tenerse en cuenta las diferencias biológicas que hay entre las mujeres y el hombre y las diferencias que la sociedad y la cultura han creado. En ciertas circunstancias será necesario que haya un trato no idéntico de mujeres y hombres para equilibrar esas diferencias (consideración 14²).

Y, además, específicamente, en el ámbito del trato debido a la mujer privada de libertad y en estado de gravidez, la Corte (2016) recurre al Comité de Derechos Humanos en su Observación General № 28 sobre igualdad de derechos entre hombres y mujeres, en su artículo 3 (15), que refiere que:

Las mujeres embarazadas que estén privadas de libertad deben ser objeto de un trato humano y debe respetarse su dignidad inherente en todo momento, y en particular durante el alumbramiento y el cuidado de sus hijos recién nacidos. Los estados partes deben indicar qué servicios tienen para garantizar lo que antecede y qué formas de atención ofrecen a esas madres y a sus hijos (consideración $14^{\circ}$ ).

\subsection{Niños, niñas y adolescentes y discriminación estructural}

En el año 2018, la Corte Suprema conoció de otro caso sorprendente. Bajo el manto de un supuesto control de identidad, un grupo de carabineros ingresaron a un 
predio en el que se encontraban varios niños mapuches, obligándolos a desnudarse como parte de dicho control (Cooperativa, 2018; El Desconcierto, 2018). Nosotros ya habíamos alertado acerca de los riesgos que implicaban para el disfrute pleno de los derechos humanos el denominado control preventivo de identidad y de los abusos a los que este podía conducir (Centro de Estudios Constitucionales de Chile. Cecoch, 2016). Una de las razones que habíamos proporcionado era que se corría un grave riesgo de afectar los derechos de los niños, niñas y adolescentes, respecto de los cuales el Estado y sus agentes tienen un deber especial de garante. En este caso, la diferencia de trato proporcionada por Carabineros podría haber estado vinculada, entre otras cosas, con el hecho de que se trataba de un grupo de niños mapuches.

La Corte Suprema (2018a) acogió el recurso de amparo presentado en este caso en favor de los niños mapuches, invocando como norma decisoria litis la Convención sobre los Derechos del Niño de 1989, y aplicando criterios de interpretación propios de los derechos humanos, tales como el principio pro homine. En efecto, los jueces supremos señalaron que:

Las facultades de los policías para detener o retener a un ciudadano en la vía pública con el objeto de interrogarlo o registrarlo, están expresamente regladas en la ley, pues constituyen una limitación o restricción al derecho a la libertad personal, así como a los derechos a la privacidad, intimidad y a guardar silencio consagrados constitucionalmente, facultades que, además, por disposición del artículo 5, inciso $2^{\circ}$, del Código Procesal Penal, deben interpretarse restrictivamente.

En momento en que escuchamos permanentemente a través de los distintos medios de difusión que hay que proteger a los niños, niñas y adolescentes de nuestras sociedades, que ellos son el futuro del país, y que le corresponde al Estado asumir un rol esencial en todo esto, este tipo de acontecimientos, caen como un balde de agua fría, y nos regresan a la realidad cotidiana de vulnerabilidad creciente de mucho niños, niñas y adolescentes indígenas.

\subsection{Personas con discapacidad y discriminación interseccional}

En el caso del Colegio Alemán de Puerto Varas, (Colegio Alemán I), de 6 de noviembre de 2017, esta corporación no modificó o ajustó de manera razonable sus procedimientos de admisión para el año escolar 2018 respecto de una niña que se encontraba en imposibilidad de participar en las fechas fijadas, debido a padecimientos físicos sufridos producto de la hidrocefalia derivada del mielomeningocele congénito que le aquejaba. Entonces, en este caso, el juez se encuentra frente a una menor de edad, de sexo femenino, y con discapacidad. 
Al igual que ocurrió en los casos anteriores, la Corte Suprema tomó en consideración como norma decisoria litis la Convención sobre Derechos de las personas con discapacidad -vigente en nuestro país desde 2008-, además de las normas pertinentes de la Ley 20.422 relativas a los derechos de las personas con discapacidad. Es así como, la Corte reitera el artículo 24 de la mencionada Convención, el cual reconoce el derecho a la educación de las personas con discapacidad en todos los niveles, para lo cual deben efectuarse ajustes razonables, y que es un deber del Estado garantizar el goce efectivo de este derecho. Uno de los grandes aportes que efectúan los jueces del máximo tribunal, es el reconocimiento explícito de que los derechos humanos-el derecho a la igualdad y el derecho de acceso a la educación, en este caso- obligan a todos, tanto a los órganos del Estado como a los particulares. Con esto, queda claro para la Corte, que los derechos humanos pueden ser vulnerados tanto por el Estado como por los particulares. Por esta razón, la Corte Suprema (2017, Rol n. ${ }^{036.694-2017) ~}$ afirmó lo siguiente:

Que, como se puede apreciar, del tenor de las reglas transcritas se desprende con claridad que todo prestador de servicios educacionales, sea público o privado, tiene la obligación de adecuar su procedimiento de selección para asegurar igual trato a personas con discapacidad, exigencia que debe entenderse incumplida por la Corporación Colegio Alemán de Puerto Varas, desde que, puesta en conocimiento de la imposibilidad física de la niña para asistir a la entrevista personal y jornadas de observación durante mayo de 2017 (...) accedió sólo parcialmente a la solicitud de los padres, reprogramando tales actividades para el 30 y 31 de mayo, frustrando con ello su participación en el proceso de admisión (consideración $5^{\circ}$ ).

En este caso, se echa de menos el auxilio interpretativo que podría haber proporcionado la jurisprudencia de la Corte Interamericana de Derechos Humanos en cuanto a los estándares en materia de prohibición de la discriminación. Con todo, el uso de la Convención sobre Derechos de las personas con discapacidad ya es un paso relevante.

Finalmente, vale la pena mencionar que la Corte Suprema (2017) reconoce, en este caso, como principio de interpretación en derechos humanos, el principio de optimización, expansivo o de máxima eficacia, sobre todo, en relación con las normas internacionales. En efecto, la Corte Suprema sostiene que

La conducta reprochada posee la aptitud suficiente para perturbar, respecto de la niña, el derecho a la igualdad que la Carta Fundamental le asegura a todas las personas en el numeral $2^{\circ}$ de su artículo 19 , derecho cuya optimización constituye el objetivo primordial de las normas infringidas, al ordenar un trato diferenciado entre sujetos que se encuentran en condiciones dispares, promoviendo, así, la ecuánime participación en la admisión al sistema educacional respecto de todos los postulantes, más allá de sus circunstancias físicas (consideración $6^{\circ}$ ). 


\subsection{Personas con discapacidad y discriminación estructural}

En el caso de la Empresa de Transportes de Pasajeros Metro S. A. (Metro), de 25 de julio de 2018, la señora Jeannette Sandoval Camarada reclama un trato discriminatorio de parte de esta empresa. La señora Sandoval presenta una discapacidad física equivalente al 70\% y se moviliza en silla de ruedas eléctrica. El día 19 de mayo de 2016, en la Estación Santa Isabel, todos los pasajeros del Metro fueron evacuados del tren y de la estación, debido a la presencia de un supuesto artefacto explosivo, salvo ella, quien tuvo que permanecer en la estación. La razón fue porque la estación no poseía medidas de accesibilidad para personas con capacidades especiales, esto es, un salva escaleras, o bien estaba averiado. Este caso es demostrativo de una falla estructural en el sentido de la escasa o nula preparación e interés, de parte de los órganos del Estado y de los particulares, de procurar el acceso de las personas con discapacidad al goce efectivo de los derechos, ya sea que se trate de acceso físico, acceso económico, acceso cultural, adecuado. Estos criterios, de accesibilidad, adaptabilidad, adecuación en el goce de los derechos ya han sido, en el pasado, desarrollados por los órganos de tratados de Naciones Unidas, por lo que ellos podrían ser utilizados por los órganos jurisdiccionales como complemento de su argumentación.

Un avance relevante que es digno de destacar es la ampliación en el uso de las normas internacionales invocadas por la Corte Suprema para desarrollar su argumentación. En efecto, los jueces recurren a la Convención Interamericana para la Eliminación de todas las Formas de Discriminación contra las Personas con Discapacidad, vigente desde 2002 en Chile, y, además, a la Convención de las Naciones Unidas sobre los Derechos de las Personas con Discapacidad y su Protocolo Facultativo, como se ha dicho, vigente desde 2008 en Chile. Estas son normas que la doctrina denomina de hard law (Cihangir, 2017). Pero, al mismo tiempo, la Corte Suprema, amplía su horizonte interpretativo, y recurre a la Declaración de la Asamblea General de las Naciones Unidas acerca de los Derechos de los Impedidos de 1975, y, además, a la Resolución adoptada por la Asamblea General en 1994, que contiene Normas Uniformes sobre la Igualdad de Oportunidades para las Personas con Discapacidad. La doctrina denomina estas normas como soft law (Toro, 2006; Colmegna, 2012). Por cierto, la sentencia se refiere a las normas nacionales de la Ley 20.422, pero incluso, interpretando esta ley, la Corte Suprema alude al Mensaje Presidencial, el cual se basa, en parte, en el Programa de Acción Mundial sobre las Personas con Discapacidad de las Naciones Unidas, aprobado por Resolución 37/52 de la Asamblea General. Esto es, la ley que regula los derechos de las personas con discapacidad se inspira y orienta en las normas internacionales al respecto, lo cual debería ser un elemento determinante al momento de adoptar la decisión jurisdiccional. Por esta razón, la propia Corte Suprema (2018b, Rol N $\left.{ }^{\circ} 41.388-2017\right)$ en un fallo unánime, afirma que, de acuerdo con lo dispuesto en el artículo 5 inciso $2^{\circ}$ de la Constitución Política de la República, esta normativa 
internacional - hard law y soft law incluido- configuran lo que se denomina el bloque constitucional de derechos fundamentales (consideración $\left.2^{\circ}\right)^{7}$.

En efecto, la Corte Suprema (2018b) utiliza en su razonamiento el concepto de discriminación, de discapacidad y de ajustes razonables contenidos en la Convención de las Naciones Unidas sobre los Derechos de las Personas con Discapacidad, con lo que amplía los contornos y los contenidos de los derechos, efectuando una interpretación de la Ley 20.422 conforme al derecho internacional (consideraciones $5^{\circ}$ y 6$)^{8}$.

¿Y, cuál es esa orientación? La Corte Suprema (2018b) lo señala claramente:

Dicha normativa internacional, como se advierte, es clara en orden a que las personas con capacidades especiales gozan los mismos derechos fundamentales que todo ser humano, que deben ser respetados, y que cualquier acto u omisión que se traduzca en una discriminación en razón de su discapacidad, afecta no solo su dignidad sino la igualdad en el ejercicio de dichos derechos (consideración $2^{\circ}$ ).

¿Cuál es la consecuencia de este razonamiento? De acuerdo con los jueces del máximo tribunal:

En ese contexto, no es atendible la única alegación que la demandada formuló al informar al tenor de la demanda, en el sentido que no estaba obligada a dar cumplimiento a la normativa nacional e internacional a que se ha hecho referencia, porque el artículo primero transitorio de la Ley $\mathrm{N}^{\circ}$ 20.422, publicada en el Diario Oficial el 10 de febrero de 2010, le otorgó un plazo de ocho años a contar de dicha data para hacer accesible y utilizable en forma autovalente y sin dificultad por personas con discapacidad, especialmente por aquellas con movilidad reducida, el acceso a los medios de transporte público de pasajeros; (...) con todo, aceptar dicho planteamiento implica que las personas discapacitadas estuvieron prácticamente privadas de usar la red subterránea de transporte público de la demandada hasta el mes de febrero de 2018, lo que se traduce en una grave conculcación a los derechos y libertades fundamentales de que son titulares y a la normativa internacional mencionada que precisamente persigue promoverlos, protegerlos y asegurarlos (2018b, consideración $4^{\circ}$ ).

Y, luego, la Corte Suprema agrega, muy interesantemente, que las normas de estos Convenios Internacionales antes mencionados "elevan a la categoría de fundamental el derecho de las personas a no verse sometidos a discriminación basada en la discapacidad, por tratarse de uno que dimana de la dignidad y la igualdad que son inherentes a todo ser humano" (2018b, consideración $7^{\circ}$ ). ¿Qué sería esto sino es control de convencionalidad en relación con el derecho a la igualdad y la prohibición

7 Sobre la noción de bloque: Rodríguez, 2017b, p. 60; desde un punto de vista comparado: Arango, 2004, pp. 79-102.

8 A título ejemplar Miranda y Navarro, 2014, pp. 69-80. 
de la discriminación? Nos parece que un control de convencionalidad en esta materia realizado por los jueces nacionales, como jueces comunes de derechos humanos, sería un paso adelante en el proceso de eliminación de la discriminación estructural que sufren las personas con discapacidad en Chile en el goce efectivo de sus derechos.

\subsection{Personas con discapacidad y alteración del onus probandi}

En el caso del Colegio Alemán de Puerto Varas, (Colegio Alemán II) de 21 de junio de 2018, esta corporación no permitió que un niño, con síndrome de Down, pasara de curso a primero básico, haciéndolo repetir la educación parvularia contra la voluntad de sus padres. En principio, el argumento del Colegio fue que el Proyecto Piloto de integración para postulantes con síndrome de Down solo estaba previsto para Kinder (nivel inicial) y que los padres del niño lo sabían, y luego, agregaron que en la evaluación de los requerimientos exigidos en la educación parvularia para ser promovido a primero básico, el niño no había alcanzado un nivel de autonomía, control y lenguaje suficientes. En este caso, al igual que ocurre en todos los casos anteriores, la Corte Suprema (2018c, Rol N³8.521-2017) realiza un:

a) Control de convencionalidad. En este caso, de la Convención de las Naciones Unidas sobre los derechos de las personas con discapacidad y su Protocolo Facultativo de 2008, la Convención Interamericana para la Eliminación de todas las formas de Discriminación contra las personas con discapacidad de 2002, y la Convención sobre los Derechos del Niño de 1990 (consideración 4);

b) Aplica directamente las convenciones internacionales de derechos humanos. En efecto, la Corte Suprema señala que:

El demandado no actuó conforme a una justificación razonable (...) de manera que así, superficialmente, pasa a preferirse la excepción y a preterirse la finalidad de amparo que el ordenamiento ha venido a establecer, con manifiesta vulneración no sólo de ese precepto, sino, además, del artículo 24 de la Convención de las Naciones Unidas sobre los derechos de las personas con discapacidad; del 13.1 del Pacto Internacional de Derechos Económicos, Sociales y Culturales (...) que impedían al establecimiento educacional vetar el ingreso a la educación básica por insatisfacción en la actuación de T. en la parvularia (2018c, consideración $8^{\circ}$ ).

c) Utiliza las normas internacionales y su interpretación para completar o como complemento de las normas sobre igualdad y prohibición de la discriminación, vigentes en el ordenamiento interno, y en la argumentación persuasiva para arribar a su decisión. En efecto, la Corte Suprema (2018c) señala que "como ha dicho la jurisprudencia internacional, para que el trato diferenciado no constituya discriminación, no sólo requiere de una justificación objetiva y razonable, sino también, 
debe perseguir un fin legítimo" (consideración $10^{\circ}$ ). Se puede entender de esta afirmación que la referencia a la jurisprudencia internacional corresponde a la Corte Interamericana de Derechos Humanos. Pero, además, su argumentación en materia de prohibición de la discriminación respecto del acceso a la educación es aún más clara. De este modo, indica que:

Si bien puede entenderse que el colegio no se sienta totalmente preparado o con las herramientas necesarias para afrontar este desafío, la responsabilidad asumida al aceptar al niño como parte de la comunidad escolar, implica que debía hacer, progresivamente, los ajustes pertinentes en su proyecto educativo, en su personal docente, en la comunidad escolar y en las exigencias hacia la familia del niño, para que este no quedara excluido del sistema general de educación, como establece la Convención de las Naciones Unidas sobre los derechos de las personas con discapacidad, precisamente en este aspecto. Lo anterior implica, ciertamente, que no se ha acreditado debidamente la finalidad legítima que subyace a la medida tomada por la demandada (2018c, consideración $10^{\circ}$ ).

d) Recurre a principios de interpretación propios de los derechos humanos, aplicados en el caso concreto, a la igualdad y la prohibición de la discriminación. En el cas d'espèce, la Corte Suprema (2018c) usa el principio pro homine. En su vertiente interpretativa, esto significa que el juez debe interpretar un derecho de la manera más favorable para el individuo y sus limitaciones de la manera más restrictiva?. En efecto, en el ámbito del derecho de acceso a la educación de las personas con discapacidad este debe interpretarse extensivamente, y:

Contrario sensu, la sola aceptación de una matrícula pesa sobre el establecimiento en términos de no poder ponerle coto sino en circunstancias excepcionales que, por su misma naturaleza, quedan necesariamente sujetas a una aplicación restrictiva, cuanto más si, como en la especie, conciernen a un niño con necesidades especiales al que el colegio acogió con pleno consentimiento (consideración $5^{\circ}$ ).

Pero, en nuestra opinión, por mucho, el aporte más interesante de esta decisión judicial tiene relación con el onus probandi o carga de la prueba. Cuando estamos frente a denuncias de vulneración de derechos humanos, uno de los efectos propios de estos derechos, es la alteración del peso de la prueba, en el sentido de que existiendo indicios suficientes, la carga de la prueba le corresponde al denunciado. En doctrina, este atributo se ha denominado el efecto corrector de los derechos humanos (Aguilar y Contreras, 2007; Uribe y González, 2015). En el caso específico de la prohibición de la discriminación, la noción misma de categoría sospechosa quiere decir precisamente esto. Si el juez tiene indicios suficientes de que se ha realizado una diferencia de

9 A título ejemplar se puede ver Corte Suprema de Chile, 2018d, consideración 6; Nique de la Puente, 2016, pp. 23-34. 
trato por alguna categoría sospechosa, por ejemplo, discapacidad, debe operar en el procedimiento una alteración del onus probandi ${ }^{10}$.

Así lo ha sostenido la jurisprudencia de la Corte Interamericana de Derechos Humanos (2016, párr. 106) y así lo afirmó la Corte Suprema (2018c) en el caso de marras:

Sobre el particular es menester señalar que, aunque no lo diga explícitamente la ley en comento, tratándose de una denuncia de lesión a derechos fundamentales, el peso de la prueba ha de recaer en el denunciado, quien deberá probar los fundamentos, la razonabilidad y proporcionalidad de la medida impugnada -siempre que existan indicios de tal vulneración- cuestión que no aparece satisfecha en autos.

En efecto, desde esa perspectiva, a la demandada correspondía acreditar, despejando las dudas más arriba planteadas, cuál era la verdadera razón de la restricción impuesta a T. y en el evento de decantarse por la justificación técnica (sic) invocada, era de su cargo probar cómo es que la evaluación que efectuó respecto de las capacidades - o incapacidades- del niño hacían indispensable mantenerlo en kínder, haciéndose cargo de lo que la literatura especializada y las investigaciones en la materia señalan. (...) [Lo contrario significal poner sobre los hombros de quienes reclaman una discriminación en razón de una discapacidad, la carga de probar que era posible que el niño avanzara a primero básico como cualquier otro niño, en vez de exigir que sea quien sostiene lo contrario que lo acredite, en la medida que esto último supone una vulneración de su derecho a disfrutar en igualdad de condiciones su derecho a la educación en un establecimiento educacional regular -no especial- que le había permitido su ingreso (consideración $7^{\circ}$ ).

\subsection{Trabajadores y categorías prohibidas}

En el caso del Sindicato de Trabajadores Central de Restaurantes Aramark Limitada n. ${ }^{\circ}$ 2 (Aramark), de 5 de agosto de 2015, la organización colectiva reclama por una diferencia de trato económico respecto de otro grupo de trabajadores, en circunstancias que las diferencias relativas a las labores que desempeñan unos y otros trabajadores, así como el lugar y condiciones en que lo hacen, no son significativas para autorizar la desigualdad de trato y no justifican que las asignaciones de zona y bono de responsabilidad le sean pagados a unos y no a otros.

La cuestión que debía resolver la Corte Suprema (2015, Rol N²3.808-2014) consistía en que si esta causal, de trato económicamente diferente entraba entre las causales prohibidas de discriminación por el ordenamiento nacional, considerando la Constitución y los convenios internacionales. Finalmente, el tribunal debe

10 Cabe tener presente que, bajo la influencia del derecho internacional de los derechos humanos, esta idea de la alteración del peso de la prueba en procedimientos de amparo de derechos humanos, ya se encuentra presente en el ordenamiento chileno, bajo una fórmula específica, a través de la denominada acción de tutela de derechos fundamentales de los trabajadores regulada en el Código del Trabajo. 
decidir si las categorías prohibidas de discriminación enumeradas en el artículo 2 del Código del Trabajo, constituyen un numerus clausus o, más bien, un numerus apertus. Según la Corte,

Esta última cuestión resulta ser fundamental, por cuanto de entenderse que se trata de un catálogo cerrado o taxativo, la norma legal otorgaría una protección contra la discriminación más limitada que aquella que declaran otorgar tanto el artículo 19 $\mathrm{N}^{\circ} 16$ inciso tercero de la Constitución Política, reforzado a su vez por el artículo 19 $\mathrm{N}^{\circ} 2$ de la misma, que garantiza la igualdad ante la ley, como el Convenio 111 sobre la discriminación en materia de empleo y ocupación, adoptado por la Organización Internacional del Trabajo el año 1958 (consideración 6²).

En otras palabras, si se entiende que el artículo 2 del Código del Trabajo es un catálogo cerrado y, por lo tanto:

Importaría concluir que nuestro procedimiento de tutela laboral protege sólo parcialmente el derecho a la no discriminación, excluyendo actuaciones basadas en otros criterios, los no previstos expresamente en la norma laboral, que el legislador nacional sí ha prohibido por otras vías de mayor rango legal, como son la propia Constitución Política de la República y el ya citado Convenio OIT n. 111 de 1958, al cual le resulta plenamente aplicable lo dispuesto en el artículo $5^{\circ}$ inciso segundo de la Carta Fundamental (2015, consideración $7^{\circ}$ ).

Esta conclusión es absurda, incoherente y contraria al principio pro homine ${ }^{11}$. Por consecuencia, la respuesta a la que llega la Corte Suprema es que constituye una enunciación abierta y no exhaustiva de categorías prohibidas. Esto concuerda con la afirmación de que los derechos humanos se inspiran en valores comunes superiores y consagran obligaciones de carácter esencialmente objetivo, cuya interpretación "tiene que acompañar la evolución de los tiempos y las condiciones de vida actuales" (Corte IDH, 2005, párr. 104-106). Cabe destacar que la Corte Suprema le asigna a la Constitución, como es natural, y al Convenio n. ${ }^{\circ} 111$ de la Organización Internacional del Trabajo de 1958, el carácter de normas de un rango mayor al legal. Quizás para otros ordenamientos jurídicos, esto último ya sea un acervo constitucional adquirido, pero, en nuestro caso, esta declaración es un gran paso. Efectivamente, finalmente, la sentencia (Corte Suprema, 2015) afirma que:

11 "La correcta interpretación de la materia de derecho es aquella que determina que la protección a la garantía de no discriminación o principio de igualdad, otorgada por el procedimiento de tutela laboral -de conformidad a lo dispuesto en el artículo 485 inciso segundo del Código del Trabajo-, no queda limitada únicamente a aquellos actos discriminatorios basados en los motivos o criterios que expresamente prevé el artículo $2^{\circ}$ inciso cuarto del Código del Trabajo, sino que se extiende a todas aquellas discriminaciones o diferencias arbitrarias, prohibidas por el artículo $19 n{ }^{\circ} 16$ inciso tercero de la Constitución Política de la República y por el Convenio OIT n. 111 de 1958" (Corte Suprema de Chile, 2015, consideración 10 Corte IDH, 1985, La colegiación obligatoria de periodistas, opinión consultiva, párr. 52; 2005, párr. 106; 2012, párr. 84. 
Resultando del todo evidente que el catálogo contemplado en el artículo $2^{\circ}$ del Código del Trabajo no puede en caso alguno tener pretensiones de exhaustividad, no sólo por resultar más acotado que la protección otorgada por la norma constitucional, sino porque también ha sido superado por normas posteriores que han ampliado dicho catálogo de conductas o criterios sospechosos (consideración $8^{\circ}$ ).

Y, la misma decisión judicial, aludiendo a las normas posteriores, se refiere a la Convención Interamericana Contra toda Forma de Discriminación e Intolerancia, adoptada por la Organización de Estados Americanos en sesión del 5 de junio de 2013, la cual contiene, entre otros, un concepto amplio de discriminación, que completa y complementa la normativa interna.

Por último, en este control de convencionalidad, la Corte Suprema (2015) recurre al principio de interpretación conforme, en su doble vertiente de interpretación conforme a la Constitución e interpretación conforme a los tratados o convenios internacionales $^{12}$. En consecuencia, de acuerdo con los jueces del máximo tribunal, la norma del artículo 2 del Código del Trabajo debiera interpretarse de manera conforme con la Constitución (artículo 19 n. ${ }^{\circ}$ 16) y "con aquellos tratados y convenios internacionales suscritos y ratificados por nuestro país, de los que surgen obligaciones que no pueden ser limitadas por una norma de rango inferior, menos aún en atención al principio protector que inspira la legislación laboral, y que no sólo debe guiar la actuación del legislador, sino también la del intérprete" (2015, consideración 9²). Cabe aclarar que este principio protector en materia laboral corresponde a la especificación del principio pro homine.

En los casos antes mencionados se ha usado, en los razonamientos jurídicos, principalmente las normas convencionales internacionales y, en menor medida, la interpretación autorizada del órgano internacional competente, por lo que se puede sostener que ha habido un control de convencionalidad. Con todo, en esta materia, la articulación del juez con el derecho internacional podría ser más intensa, aunque ha ido incrementándose. Y, decimos que podría ser más intensa, porque en materia de prohibición de la discriminación es la propia Ley 20.609, que establece medidas contra la discriminación, la que en su artículo $1^{\circ}$ inciso $2^{\circ}$, realiza una alusión a los tratados internacionales ratificados por Chile. Como es sabido, este mismo fenómeno se produce a nivel constitucional. En efecto, el artículo 19 n. ${ }^{\circ} 2$ reconoce el derecho a la igualdad y la prohibición de la discriminación en términos generales. Y, es el mismo texto constitucional, en su artículo $5^{\circ}$ inciso $2^{\circ}$ de la Constitución, el que, en materia

12 Caballero, 2013, in passim; "la cláusula de interpretación es la técnica mediante la cual los derechos humanos reconocidos en la Constitución son armonizados con las disposiciones normativas previstas en los instrumentos internacionales ratificados por el Estado y por la jurisprudencia internacional, con el fin de ampliar el margen de vigencia y protección de los derechos humanos y, por ende, potenciar el principio pro persona"; Rodríguez, 2017a, p. 36; Ferrer, 2011, pp. 531-622; Silva García, 2014, pp. 251-272). 
de derechos humanos, reenvía a los tratados internacionales. Establecer si los jueces nacionales realizan un efectivo control de convencionalidad resulta de la máxima relevancia por diversos motivos. En primer lugar, porque se cumple con una obligación internacional; en segundo lugar, porque se instaura un diálogo entre jurisdicciones en búsqueda del estándar más favorable para el individuo, con el consiguiente beneficio para la comunidad toda; en tercer lugar, porque se satisface efectivamente el principio de complementariedad. Y, finalmente, porque se produce un efecto económicopreventivo, evitando ser emplazado en instancias internacionales. En efecto, la propia Corte IDH ha señalado que "cuando una cuestión ha sido resuelta definitivamente en el orden interno según las cláusulas de la Convención, no es necesario traerla a esta Corte para su 'aprobación' o 'confirmación'” (Corte IDH, 2016, párr. 127)'13.

A la luz de los casos analizados precedentemente, se podría sostener que la Corte Suprema de Chile efectúa un control de convencionalidad en las sentencias mencionadas sobre discriminación. En general, la operación de control de convencionalidad es implícita, pero, de todas formas, se puede apreciar que, en estos casos, el juez vela por el cumplimiento de las obligaciones contenidas en los instrumentos internacionales de derechos humanos. Incluso, en ocasiones incorpora los criterios y estándares elaborados por la jurisprudencia internacional e interamericana de derechos humanos.

\section{CONCLUSIONES}

Los casos que hemos examinado apuntan al corazón de los grandes desafíos que enfrenta la sociedad chilena contemporánea. Se trata de desafíos de gran envergadura, donde las normas de protección de los derechos humanos y la actuación pertinente de nuestros tribunales son necesarias, más no suficientes. La amenaza de la discriminación en cualquiera de sus categorías prohibidas es omnipresente.

El Estado tiene el deber de desarrollar las políticas públicas necesarias para hacer frente a este flagelo. En este ámbito, en particular, los jueces nacionales han demostrado en casos concretos que han ido, en forma creciente, aplicando un control de convencionalidad. Con el objeto de proporcionar protección al derecho a la igualdad y sancionar la vulneración de la prohibición de la discriminación, el control normativo internacional ha sido acabado, incluyendo tanto el hard law como el soft law. Adicionalmente, como ocurrió en el caso Cayuhan, las decisiones judiciales usan en su razonamiento las opiniones de los órganos de tratados de Naciones Unidas. También se aprecia en todos los casos que las normas convencionales internacionales forman parte del parámetro de protección interno de los derechos humanos. En definitiva, en

13 Sobre el diseño de protección multinivel al interior del sistema interamericano de protección de los derechos humanos: Corte IDH, 2001, caso Las Palmeras vs. Colombia, párr. 33; 2014c, caso Tarazona Arrieta y otros vs. Perú, pár. 136. 
todos los casos, el control de convencionalidad sirvió para complementar, completar y mejorar el nivel de protección interno relativo a la prohibición de la discriminación. Cabe destacar que en los casos como en Aramark, la Corte Suprema, argumentando en función de las normas constitucionales y convencionales internacionales, resolvió la controversia aplicando la interpretación más favorable o más protectora. De este modo, se puede observar en los casos analizados, que el control de convencionalidad se encuentra asimismo conectado con un razonamiento jurídico desformalizado en el ámbito de los derechos humanos.

Además, varios casos, como Cayuhan, Colegio Alemán I y Colegio Alemán II, son el fiel reflejo de una discriminación interseccional. Salvo en el caso Cayuhan, la Corte Suprema no utiliza esta elaboración interamericana, pudiendo haberlo hecho. Definitivamente, todos los casos, como Cayuhan, niños mapuches o Metro, exponen situaciones de discriminación estructural, que responden a razones históricas, culturales o sociales.

Los particulares, como componentes de la sociedad, también tienen la obligación de prevenir la discriminación. Las instituciones de educación, en todos los niveles del proceso de formación del niño, niña y adolescente, están llamadas a jugar un rol clave y de largo aliento en esta materia. La erradicación de la discriminación en nuestras sociedades es un tema cultural que debe abordarse, entre otros lugares, en las aulas. Parafraseando las palabras del preámbulo de la Constitución de la Organización de las Naciones Unidas para la Educación, la Ciencia y la Cultura de 1945, "puesto que la discriminación nace en la mente de los hombres, es en la mente de los hombres donde deben erigirse los baluartes de la igualdad".

\section{REFERENCIAS}

Acosta Alvarado, P. (2013). El pluralismo constitucional como respuesta a los desafíos de la protección multinivel en Latinoamérica. Comentarios a la propuesta de René Urueña. Revista Derecho del Estado, (31), 347-368.

Aguilar Cavallo, G. (2017). Justicia constitucional, rol del juez y diálogo jurisdiccional: el caso de Chile. Anuario Iberoamericano de Justicia Constitucional, (21), 1-36.

Aguilar Cavallo, G. y Contreras Rojas, C. (2007). El efecto horizontal de los Derechos Humanos y su reconocimiento expreso en las relaciones laborales en Chile. Revista Ius et Praxis, 13(1), 205-24.

Ansuátegui Roig, F. (2015). Derechos humanos y diálogo judicial entre América y Europa: ¿Hacia un nuevo modelo de derecho? Tigor: Rivista di Scienze della Comunicazione e di Argomentazione Giuridica, $\operatorname{VII}(2), 3-18$.

Arango Olaya, M. (2004). El Bloque de constitucionalidad en la jurisprudencia de la Corte Constitucional Colombiana. Precedente. Anuario Jurídico, 79-102. 
Caballero Ochoa, J. (2013). La interpretación conforme. El modelo constitucional ante los tratados internacionales sobre derechos humanos y el control de convencionalidad. México: Porrúa-IMDPC.

Camarillo Govea, L. (2016). Convergencias y divergencias entre los sistemas europeo e interamericano de derechos humanos. Revista Prolegómenos, I, 67-84.

Carrillo Santarelli, N. y Espósito, C. (2011). Los jueces nacionales como garantes de bienes jurídicos humanitarios. Revista Española de Derecho Internacional, LXIII, (2), 51-85.

Castilla Juárez, K. (2016). La independencia judicial en el llamado control de convencionalidad interamericano. Estudios Constitucionales, 14(2), 53-100.

Castilla Juárez, Karlos A. (2014) Control de convencionalidad interamericano: una mera aplicación del derecho internacional. Revista Derecho del Estado, (33), 149-172.

Català I Bas, A. H. (2015). Diálogo entre tribunales y creación de un sistema de protección de derechos humanos abierto en Red. Revista Europea de Derechos Fundamentales, (28), 13-47.

Centro de Estudios Constitucionales de Chile (CECOCH). (2016) Control preventivo de identidad y derechos humanos. Recuperado de http://www.cecoch.cl/publicacion/control-preventivo-de-identidad-y-derechos-humanos/index.htm

Cihangir, N. (2017). The Role of Soft Law and the Interplay between Soft Law and Hard Law in the Context of International Human Rights. Law \& Justice Review, 8(14), 201-219.

Colmegna, P. (2012). Impacto de las normas de soft law en el desarrollo del derecho internacional de los derechos humanos. Revista Electrónica del Instituto de Investigaciones Ambrosio L. Gioja, VI(8), 27-47.

Comité de Derechos Humanos. (1989). Observación General n. ${ }^{\circ}$ 18. No discriminación, 10 de noviembre de 1989, CCPR/C/37. Recuperado de https://www.acnur.org/fileadmin/Documentos/ BDL/2001/1404.pdf

Contesse, J. (2013). ¿La última palabra? Control de convencionalidad y posibilidades de diálogo con la Corte Interamericana de Derechos Humanos. Recuperado de: https:/law.yale.edu/system/files/ documents/pdf/sela/SELA13_Contesse_CV_Sp_20130401.pdf

Cooperativa (2018). Denuncian que Carabineros obligó a desnudarse a niños mapuches en control policial. Recuperado de https://www.cooperativa.cl/noticias/pais/pueblos-originarios/mapuche/denuncian-que-carabineros-obligo-a-desnudarse-a-ninos-mapuche-en-control/2018-05-07/134124. html

Corte IDH. (2017). Identidad de género, e igualdad y no discriminación a parejas del mismo sexo. Obligaciones estatales en relación con el cambio de nombre, la identidad de género, y los derechos derivados de un vínculo entre parejas del mismo sexo (interpretación y alcance de los artículos 1.1, 3, 7, 11.2, 13, 17, 18 y 24, en relación con el artículo 1 de la Convención Americana sobre Derechos Humanos). Opinión consultiva OC-24/17. Serie A n. ${ }^{\circ} 24$. Recuperado de http://www.corteidh.or.cr/docs/opiniones/seriea_24_esp.pdf 
Corte IDH. (2016). Caso Duque vs. Colombia. Excepciones preliminares, fondo, reparaciones y costas. Serie C n. ${ }^{\circ}$ 310. Recuperado de http://www.corteidh.or.cr/docs/casos/articulos/seriec_310_esp.pdf

Corte IDH. (2015a). Caso Gonzales Lluy y otros vs. Ecuador. Excepciones preliminares, fondo, reparaciones y costas. Sentencia de 1 de septiembre de 2015. Serie C n. ${ }^{\circ} 298$. Voto concurrente del juez Eduardo Ferrer MacGregor Poisot. Recuperado de http://www.corteidh.or.cr/docs/casos/ articulos/seriec_298_esp.pdf

Corte IDH. (2015b). Caso Granier y otros (Radio Caracas Televisión) vs. Venezuela. Excepciones preliminares, fondo, reparaciones y costas. Serie C n. ${ }^{\circ}$ 293. Recuperado de http://www.corteidh.or.cr/ docs/casos/articulos/seriec_293_esp.pdf

Corte IDH. (2014a). Caso Norín Catrimán y otros (dirigentes, miembros y activista del pueblo indígena mapuche) vs. Chile. Fondo, reparaciones y costas. Serie C n. 279. Recuperado de http://www. corteidh.or.cr/docs/casos/articulos/seriec_279_esp.pdf

Corte IDH. (2014b). Caso Espinoza Gonzales vs. Perú. Excepciones preliminares, fondo, reparaciones y costas. Serie C n. ${ }^{\circ}$ 289. Recuperado de http://www.corteidh.or.cr/docs/casos/articulos/ seriec_289_esp.pdf

Corte IDH. (2014c). Caso Tarazona Arrieta y otros vs. Perú. Excepción preliminar, fondo, reparaciones y costas. Serie C n. ${ }^{\circ}$ 286. Recuperado de http://www.corteidh.or.cr/docs/casos/articulos/ seriec_286_esp.pdf

Corte IDH. (2012). Caso Atala Riffo y niñas vs. Chile. Fondo, reparaciones y costas, Serie C n. 239. Recuperado de http://corteidh.or.cr/docs/casos/articulos/seriec_239_esp.pdf

Corte IDH. (2010). Caso comunidad indígena Xákmok Kásek vs. Paraguay. Fondo, reparaciones y costas, Serie C n. ${ }^{0}$ 214. Recuperado de http://www.corteidh.or.cr/docs/casos/articulos/seriec_214_esp.pdf

Corte IDH. (2005). Caso de la masacre de Mapiripán vs. Colombia. Serie C n. ${ }^{\circ} 134$. Recuperado de http://www.corteidh.or.cr/docs/casos/articulos/seriec_134_esp.pdf

Corte IDH. (2003). Condición jurídica y derechos de los migrantes indocumentados. Opinión consultiva OC-18/03. Serie A n. ${ }^{\circ}$ 18. Recuperado de https://www.acnur.org/fileadmin/Documentos/ BDL/2003/2351.pdf

Corte IDH. (2002). Condición jurídica y derechos humanos del niño. Opinión consultiva OC-17/02. Serie A n. ${ }^{0}$ 17. Recuperado de http://www.corteidh.or.cr/docs/opiniones/seriea_17_esp.pdf

Corte IDH. (2001). Caso Las Palmeras vs. Colombia. Fondo. Serie C n. ${ }^{\circ}$ 90. Recuperado de http://www. corteidh.or.cr/docs/casos/articulos/Seriec_67_esp.pdf

Corte IDH. (1999). El derecho a la información sobre la asistencia consular en el marco de las garantías del debido proceso legal. Opinión consultiva OC-16/99. Serie A n. ${ }^{\circ} 16$. Recuperado de http://www. corteidh.or.cr/docs/opiniones/seriea_16_esp.pdf

Corte IDH. (1985). La colegiación obligatoria de periodistas (artículos 13 y 29 Convención Americana sobre Derechos Humanos). Opinión consultiva OC-5/85. Serie A n. ${ }^{0} 5$. 
Corte Suprema de Chile. (2018a). Rol n. ${ }^{\circ}$ 10868 - 2018. Control de identidad niños mapuches. Recurso de amparo.

Corte Suprema de Chile. (2018b). Rol n. ${ }^{\circ}$ 41.388-2017. Sandoval Camarada, Jeannette con Empresa de Transportes de Pasajeros Metro S. A. Recurso de casación.

Corte Suprema de Chile. (2018c). Cuarta sala. Rol n³8.521-2017. Recurso de protección en contra de la Corporación Colegio Alemán de Puerto Varas.

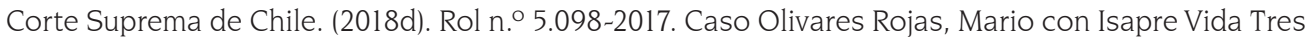
S. A. Recurso de casación.

Corte Suprema de Chile. (2017). Rol n. ${ }^{0}$ 36.694-2017. Recurso de protección en contra de la Corporación Colegio Alemán de Puerto Varas.

Corte Suprema de Chile. (2016). Rol n. 92.795-2016. Caso Lorenza Cayuhan. Acción de amparo.

Corte Suprema de Chile. (2015). Rol n. ${ }^{\circ}$ 23.808-2014. Sindicato Dos Central de Restaurantes Aramark con Sociedad Aramark Servicios Mineros y Remotos Ltda. Recurso de unificación.

Corte Internacional de Justicia (1945). Estatuto de la Corte Internacional de Justicia. Recuperado de https://www.icj-cij.org/files/statute-of-the-court/statute-of-the-court-es.pdf

Díaz Crego, M. (2016). Diálogo judicial. Eunomía. Revista en Cultura de la Legalidad, (9), 289-299.

Díaz Domínguez, L., Paz Medina, L. y González Hernández, M. (2017). El paradigma del control difuso de convencionalidad: alcances y límites a seis años de su implementación en México. Revista Jurídica Universidad Americana, 5, 91-116.

El Desconcierto. (2018). Los obligaron a desvestirse: comunidad mapuche de Ercilla denuncia amenazas de Carabineros hacia tres niños. Recuperado de http://www.eldesconcierto.cl/2018/03/23/ los-obligaron-a-desvestirse-comunidad-mapuche-de-ercilla-denuncia-amenazas-de-carabineros-hacia-tres-ninos/

Escobar-García, C. (2012). ¿Constitucionalismo global? Vicisitudes y contingencias de proceso a partir de algunas experiencias en América Latina. Díkaion, 21(1), 79-118.

Iglesias Vila, M. (2017). Subsidiariedad y tribunales internacionales de derechos humanos: ¿deferencia hacia los Estados o división cooperativa del trabajo? Derecho PUCP. Revista de la Facultad de Derecho, (79), 191-222.

Ferrajoli, L. (1998). Más allá de la soberanía y la ciudadanía: un constitucionalismo global. Isonomía, (9), 173-184.

Ferrer MacGregor, E. (2011). Interpretación conforme y control difuso de convencionalidad. El nuevo paradigma para el juez mexicano. Estudios Constitucionales, 9(2), 531-622.

Fuentes, X. (2007). El derecho internacional y el derecho interno: definitivamente una pareja dispareja. Revista de Economía y Derecho, 15(4), 2-35 
Fuenzalida Bascuñán, S. (2015). La jurisprudencia de la Corte Interamericana de Derechos Humanos como fuente de derecho. Una revisión de la doctrina del "examen de convencionalidad". Revista de Derecho, XXVIII(1), 171-192.

Guastini, R. (1999). Sobre el concepto de Constitución. Cuestiones Constitucionales, (1), 161-176.

Henríquez Viñas, M. (2014). La polisemia del control de convencionalidad interno. International Law. Revista Colombiana de Derecho Internacional, (24), 113-141.

Jinesta L. E. (2012). Control de convencionalidad ejercido por los tribunales y salas Constitucionales. En E. Ferrer MacGregor (Coord.), El control difuso de convencionalidad. Diálogo entre la Corte Interamericana de Derechos Humanos y los jueces nacionales (1-28). San José: Fundap.

Julios-Campuzano, A. (2009). Estado de derecho, democracia y justicia constitucional: una mirada (de soslayo) al neoconstitucionalismo. Revista de Estudos Constitucionais, Hermenêutica e Teoria do Direito (RECHTD), 1(2).

Martínez Moreno, C. (2016). El marco internacional para la tutela de los derechos laborales. Revista Jurídica de los Derechos Sociales, 6(1), 94-119.

Miranda Bonilla, H. (2015) Control de convencionalidad y diálogo judicial en el espacio interamericano de protección. Revista do Instituto de Pesquisas e Estudos, 49(64), 7-55.

Miranda Camarena, A. y Navarro Rodríguez, P. (2014). El principio de interpretación conforme en el derecho constitucional mexicano. Opinión Jurídica, 13(26), 69-80.

Molina Vergara, M. (2018). Estándares jurídicos internacionales: necesidad de un análisis conceptual. Revista de Derecho, 25(1), 233-256.

Montesinos Padilla, C. (2016-2017). Tutela multinivel de los derechos: concepto, marco teórico y desafíos actuales. Eunomía. Revista en Cultura de la Legalidad, (11).

Nogueira Alcalá, H. (2015). Los estándares de derechos humanos y el control de convencionalidad en el control de inaplicabilidad por inconstitucionalidad por parte del Tribunal Constitucional chileno en su jurisprudencia de 2014, Revista Ius et Praxis, 21(1), 653 - 676.

Nogueira Alcalá, H. (2012). Diálogo interjurisdiccional, control de convencionalidad y jurisprudencia del Tribunal Constitucional en período 2006-2011. Estudios Constitucionales, 10(2), 57-140.

Nuevo López, P. (2015). Control de convencionalidad y aplicación judicial de los derechos fundamentales de la Unión Europea. Revista Catalana de Dret Públic, (50), 141-160.

Ñique de la Puente, J. (2016). La dignidad humana y el principio pro homine. Revista Jurídica Docentia et Investigatio, 18(1) 23-34.

Núñez Donald, C. (2015). Bloque de constitucionalidad y control de convencionalidad en Chile: avances jurisprudenciales. Anuario de Derechos Humanos, (11), 157-169.

Olano García, H. (2016). Teoría del control de convencionalidad. Estudios Constitucionales, 14(1), 61-94. 
Organización de Estados Americanos. OEA. (1969). Convención Americana sobre Derechos Humanos. Recuperado de https://www.oas.org/dil/esp/tratados_b-32_convencion_americana_sobre_ derechos_humanos.htm

Pelletier Quiñones, P. (2014). La discriminación estructural en la evolución jurisprudencial de la Corte Interamericana de Derechos Humanos. Revista IIDH, 60, 205-215.

Risso Ferrand, M. (2016). El control de convencionalidad. Revista de Derecho Público, 25(50), 193-201.

Rodríguez Reveggino, B. (2017a). ¿El diálogo como arma? La lucha de los tribunales regionales contra la fragmentación del derecho internacional de los derechos humanos. Iuris Dictio, (20), 105-118.

Rodríguez, Marcos F. (2017b). Bloque de derechos humanos como parámetro de constitucionalidad y convencionalidad. Ciudad de México: Tribunal Electoral del Poder Judicial de la Federación.

Ruiz-Morales, M. (2017). El control de convencionalidad y los sistemas de protección de los derechos humanos americano y europeo. Su recepción en el caso argentino y español. Anuario Iberoamericano de Justicia Constitucional, (21), 129-160.

Silva Abbot, M. (2016). Control de convencionalidad interno y jueces locales: un planteamiento defectuoso. Estudios Constitucionales, 14(2), 101-142.

Silva García, F. (2014). Derechos humanos y restricciones constitucionales: ¿Reforma constitucional del futuro vs. interpretación constitucional del pasado? (Comentario a la C. T. 293/2011 del pleno de la SCJN). Cuestiones Constitucionales, (30), 251-272.

Toro Huerta, M. (2006). El fenómeno del soft law y las nuevas perspectivas del derecho internacional. Anuario Mexicano de Derecho Internacional, VI, 513-549.

Torres Zúñiga, N. (2015 2016). Control de convencionalidad (en el Sistema Interamericano de Derechos Humanos). Eunomía, Revista en Cultura de la Legalidad, (9), 186-194.

Uribe Alzate, E. y González, I. (2015). Los efectos de los derechos fundamentales en el tiempo. Boletín Mexicano de Derecho Comparado, XLVIII(144), 1155-1196.

Urueña, R. (2013). Luchas locales, cortes internacionales. Una exploración de la protección multinivel de los derechos humanos en América Latina. Revista Derecho del Estado, (30), 301-328. 